Revista Brasileira de Cartografia

ISSN 1808-0936 | https://doi.org/10.14393/revbrascartogr

Sociedade Brasileira de Cartografia, Geodésia, Fotogrametria e Sensoriamento Remoto

\title{
Modelagem de regressão espacial para estimava de valores em massa a partir de cartografia cadastral
}

\section{Spatial regression modeling for mass value estimation from cadastral cartography}

Felipe de Souza Pimenta ${ }^{1}$, Frederico Vasconcelos Ribeiro ${ }^{2}$ e Dionísio Costa Cruz Júnior ${ }^{3}$

1 Escola de Engenharia de Agrimensura - EEA, Programa de Pós-graduação Lato Sensu em Geotecnologias: Soluções de Inteligência Geográfica, Salvador, Brasil. E-mail: felipepimenta93@outlook.com.

ORCID: https://orcid.org/0000-0001-6635-1143

2 Universidade Estadual de Santa Cruz. Departamento de Ciências Agrárias e Ambientais, Ilhéus, Brasil. E-mail: fredvribeiro@ hotmail.com.

ORCID: https://orcid.org/0000-0002-8604-4252

3 Escola de Engenharia de Agrimensura - EEA, Programa de Pós-graduação Lato Sensu em Geotecnologias: Soluções de Inteligência Geográfica, Salvador, Brasil. E-mail: dionisiojunior@iquali.com.br.

ORCID: https://orcid.org/0000-0001-7148-9710

Recebido: 11.2019 | Aceito: 05.2020

Resumo: Esta pesquisa propôs a construção e avaliação do desempenho de modelos de regressão linear múltipla (convencional e espacial) para a cidade de Itororó (BA) e assim possibilitar elaboração de uma Planta de Valores Genéricos (PVG) e estimativa do Imposto sobre a Propriedade Predial Urbana (IPTU). Para tanto, o processo de elaboração desses modelos compreendeu mapeamento aerofotogramétrico e cadastro imobiliário, análises espaciais, de multicolinearidade, normalidade e homocedasticidade dos resíduos, além de testes dependência espacial de acordo com a NBR 14.653-2/2011. Os resultados indicaram que a incorporação dos efeitos da autocorrelação espacial através do modelo de defasagem espacial reduzido proporcionou melhor desempenho em relação ao convencional. No entanto a construção do modelo de regressão geograficamente ponderada também reduzido, capaz de modelar a heterogeneidade espacial, mostrou-se ainda mais adequado, propiciando a quase totalidade da explicação da variação dos valores preditos, além de redução brusca dos erros de predição e do coeficiente de dispersão. A extrapolação desse modelo proporcionou a elaboração da PVG e simulação do IPTU. Assim, o incremento na alíquota de $1 \%$ proporcionaria considerável participação da arrecadação interna para a receita municipal.

Palavras-chave: Econometria Espacial. Geoestatística. Cadastro Imobiliário. Aerofotogrametria. Análises Espaciais.

\begin{abstract}
This research proposed the construction and performance evaluation of multiple linear regression models (conventional and spatial) for the city of Itororó (BA) and thus enable the elaboration of a Generic Values Plant (PVG) and estimation of the Urban Property Tax (IPTU). To this end, the elaboration process of these models included aerophotogrammetric mapping, and real state register, spatial analyzes, multicollinearity, normality and homoscedasticity of the residues, as well as spatial dependence tests according to NBR 14.653-2/2011. The results indicated that incorporating the effects of spatial autocorrelation through the reduced spatial lag model provided better performance than the conventional one. However the construction of the geographically weighted regression model also reduced, able to model spatial heterogeneity, it was even more adequate, providing almost all the explanation of the predicted values variation, as well as a sharp reduction of the prediction errors and the dispersion coefficient. The extrapolation of this model provided the elaboration of PVG with total values and simulation of IPTU. Thus, the increase in the $1 \%$ tax rate would provide a considerable share of internal revenues for municipal revenue.
\end{abstract}

Keywords: Spatial Econometrics. Geostatistics. Real State Register. Aerial Photogrammetry. Spatial Analyzes.

\section{INTRODUÇÃO}

A Constituição Federal de 1988 proporcionou mais autonomia aos municípios através da descentralização das políticas públicas. No entanto, a União e os estados transferiram parte das suas 
responsabilidades para os municípios sem a correspondente transferência de recursos. Como implicações, as despesas municipais estão crescendo mais do que a receita, provocando um desequilíbrio fiscal significativo (CNM, 2018). A transferência de competências entre as esferas federal e estadual para os municípios também implica no dever de assumir adequadamente funções como a municipalização da educação e saúde pública, a concessão de serviços de saneamento, a correta tributação e a sustentabilidade ambiental. Tarefas para as quais a maioria das prefeituras está despreparada, pois é necessário embasar decisões ligadas à prestação de serviços à população e a aplicação de recursos em critérios transparentes, apoiados nas melhores bases de informações disponíveis sobre o município (DUARTE, 2014).

A tributação incidente sobre bens imóveis está diretamente relacionada ao Cadastro Territorial Urbano, pois é definida em função de alguns aspectos imobiliários como a cartografia e o cadastro imobiliário, o cadastro e mapeamento de propriedades municipais, de equipamentos urbanos, de bolsões de pobreza e ocupações irregulares (PAIVA; ANTUNES, 2017). O cálculo do Imposto sobre a Propriedade Predial Urbana (IPTU) tem como base o valor venal do imóvel, o qual deverá corresponder ao valor de venda à vista, sendo determinado pelo somatório do valor do terreno e da construção (AFONSO et al., 2010). A mensuração do terreno por exemplo, constitui um produto derivado do mapeamento cadastral urbano representando um instrumento indispensável na elaboração da base de cálculo do IPTU. Como a eficiência no lançamento e na cobrança do IPTU depende muito da atualização da Planta de Valores Genéricos (PVG) e do cadastro imobiliário, essa atualização é necessária já que os imóveis mais valorizados tendem a apresentar maior defasagem do seu valor de mercado em relação aos imóveis menos valorizados, tornando regressiva a base de cálculo do imposto (PFMB, 2015).

A partir da Lei de Responsabilidade Fiscal, os prefeitos se viram obrigados a atualizar os cadastros imobiliários urbanos, assim como efetuar a cobrança do IPTU da forma correta, sob pena de sofrerem sanções por praticarem a renúncia de receita (BRASIL, 2000). No entanto, além da desatualização do cadastro imobiliário, os pequenos municípios enfrentam dificuldades para realizar a cobrança do IPTU devido à falta de uma metodologia robusta e simplificada na determinação do valor venal dos imóveis urbanos, bem como de pessoal capacitado e de recursos financeiros. Esses municípios são os que mais carecem de informações e técnicas que se adequem à sua realidade no tocante à avaliação de imóveis, visto que é neles que ocasionalmente o IPTU nem é cobrado, deixando-se de arrecadar recursos que poderiam ser revertidos para a sociedade na forma de melhor prestação de serviços (FILHO; BRITO; GONÇALVES, 2017).

A falta de fundamentação técnico-científica na cobrança desses impostos, acarreta prejuízos aos cofres municipais e sérias injustiças tributárias à população. Por isso instrumentos que proporcionem às administrações respaldo na tomada de decisão, devem ser utilizados em conformidade com especificações técnicas, para que as deliberações políticas atinjam positivamente os serviços prestados. Dentre os meios de avaliação de imóveis disponíveis, o mais indicado pela ABNT (Associação Brasileira de Normas Técnicas) é o Método Comparativo Direto de Dados de Mercado, sendo a técnica de inferência estatística por regressão linear a mais apropriada, já que permite relacionar variáveis explicativas dos valores de mercado de elementos amostrais e obter estimativas de valores de bens avaliados (PAIVA; ANTUNES, 2017). Algumas experiências têm enfatizado a aplicação dessa técnica em alguns municípios brasileiros de pequeno e grande porte, de maneira a avaliar tanto a performance do modelo em si (BOHN; BOHN, 2016; PAIVA; ANTUNES, 2017) como da comparação de diferentes modelos através da combinação e transformação de variáveis e/ou aperfeiçoamento de modelos de regressão clássicos para modelos de regressão espaciais (DANTAS, MAGALHÃES; VERGOLINO, 2010; OLIVEIRA et al., 2016; FILHO; BRITO; GONÇALVES, 2017).

De acordo com as estimativas de população para o ano de 2018 do IBGE, 68,4\% dos municípios brasileiros possuem até 20 mil habitantes (CNM, 2017). Municípios pequenos tendem a ter uma base tributária menor, ampliando a dependência em relação às transferências intergovernamentais (PFMB, 2015). Esse é o caso do município de Itororó (Sudoeste da Bahia), com 19.914 habitantes (projeção de 20.382 hab. para 2019), em que o percentual de receitas oriundas de fontes externas representou 95,8\% no ano de 2018 e $93,38 \%$ em 2019 (TCMBA, 2019). No entanto, no cenário nacional houve um crescimento de 1,9\% da receita tributária dos municípios brasileiros no ano de 2017, como resultado do bom desempenho do IRRF (Imposto de Renda Retido na Fonte) e IPTU com crescimentos reais de 6,5\% e 4,8\% respectivamente, além do crescimento de 8,59\% do IPTU no $4^{\circ}$ bimestre do ano de 2019 em relação ao mesmo período de 2018 (CNM, 2018; 2019). 
Por isso, abordagens tecnicamente fundamentadas como a inferência estatística por regressão linear constituem potenciais instrumentos de apoio a elaboração e atualização da PVG e por consequência, o cálculo mais transparente do IPTU. Para os municípios de pequeno porte como Itororó, onde a maior contribuição para a receita tributária é externa, a elaboração da PVG por inferência estatística possibilitaria maior participação na arrecadação municipal, uma vez que o modelo é criteriosamente avaliado e o valor de mercado pode ser extrapolado para todos os imóveis da cidade. Assim, essa pesquisa propõe a construção e avaliação do desempenho de modelos de regressão linear múltipla (convencional e espacial) com base em levantamento aerofotogramétrico e cadastro imobiliário e assim possibilitar a elaboração de uma PVG, estimativa do IPTU e o impacto da arrecadação nas contas municipais.

\section{MATERIAIS E MÉTODOS}

O processo de construção de modelos de regressão linear múltipla foi basicamente segmentado em três etapas: 1) Mapeamento aerofotogramétrico; 2) Análises espaciais em ambiente de Sistemas de Informações Geográficas (SIG), e 3) Amostragem, construção e análise de modelos de regressão linear múltipla (modelo convencional e modelos espaciais) de acordo com o fluxograma da Figura 1.

Figura 1 - Fluxograma sintetizando as etapas metodológicas.

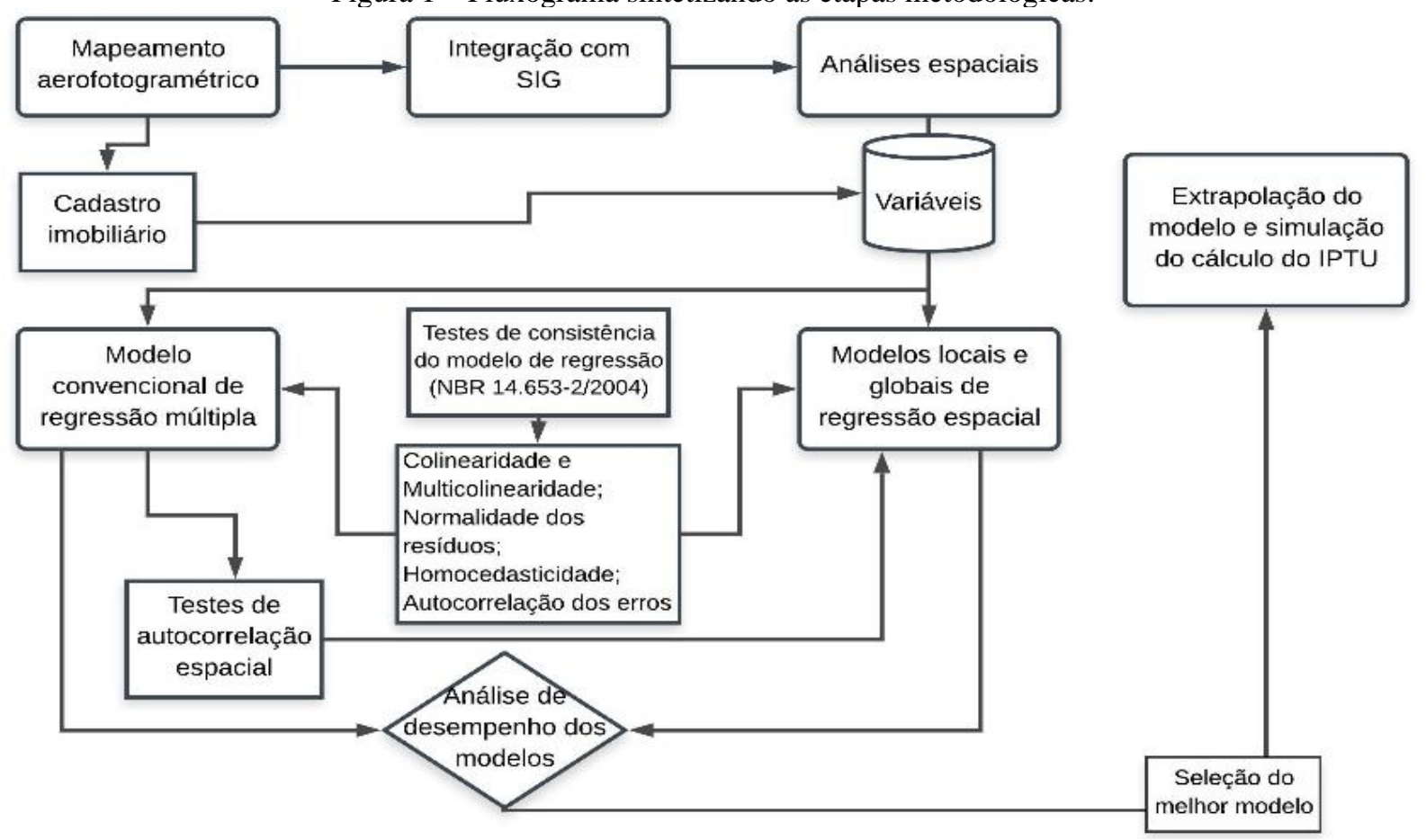

Fonte: Os autores (2021).

\subsection{Mapeamento aerofotogramétrico e cadastro imobiliário}

O mapeamento aerofotogramétrico foi realizado com um veículo aéreo não tribulado, modelo eBee (senseFly), com sensor multiespectral nas bandas do visível. A escala do levantamento foi de 1:5.000 com Ground Sample Distance (GSD) inferior a 1m para o modelo digital de elevação e inferior a 0,10m para as ortofotos digitais. O levantamento foi realizado a partir do plano de voo prévio considerando a sobreposição longitudinal e lateral mínima das fotos de 70\%. O levantamento produziu 444 fotografias aéreas que foram processadas no programa Agisoft PhotoScan. Cabe salientar que não foram utilizados pontos de controle em solo por questões logísticas. Apesar de proporcionarem alta qualidade posicional, a desconsideração desses pontos pode não promover alteração significativa de áreas e perímetros (GALVÃO; ROSALEN, 2013). O sistema geodésico de referência do projeto foi o SIRGAS2000, projeção UTM, fuso 24 S. A nuvem densa de pontos foi manipulada nos eixos ortogonais (x, y e $\mathrm{z}$ ) a fim de detectar e eliminar outliers, resultando no Ortomosaico e no Modelo Digital do Terreno (MDT) oriundo de uma classificação automática da nuvem densa 
para separar os objetos superficiais (vegetação e edificações) das cotas da superfície do solo e tratamento posterior das curvas de nível.

Os principais produtos do mapeamento aerofotogramétrico (Ortomosaico e o MDT) compuseram a base de variáveis para as análises espaciais em SIG e constituição da base cartográfica. O Ortomosaico foi vetorizado no programa ArcMap 10.3 (ESRI) para elaboração do mapeamento geométrico básico do município de Itororó, como as divisões dos lotes e logradouros que subsidiou o cadastro imobiliário mediante aplicação do Boletim de Cadastro Imobiliário (BCI), levantados por equipes de campo. Através do mapeamento geométrico básico foram mensurados a quantidade de lotes, a área e o comprimento de cada trecho de logradouro. Com o BCI foram obtidas informações sobre a utilização, o estado da construção dos imóveis, número de pavimentos e característica da fachada.

\subsection{Elaboração e análise do modelo de regressão linear múltipla convencional}

Entre as finalidades da avaliação de imóveis estão a compra e venda; identificação de valores para partilha; estudo econômico e de viabilidade para projetos e investimentos; cálculos de indenização e determinação de valores para cobrança tributária (PAIVA; ANTUNES, 2017). Dentre os meios de avaliação de imóveis disponíveis, o mais indicado pela ABNT é o Método Comparativo de Dados de Mercado. Segundo o item 8.2.1 da NBR 14.653-1, esse método identifica o valor de mercado do bem por meio de tratamento técnico dos atributos dos elementos comparáveis, constituintes da amostra. Paiva e Antunes (2017) consideram que na elaboração de uma PVG, os preços do $\mathrm{m}^{2}$ de terrenos de uma região podem ser generalizados a partir de amostras. Quando tratadas estatisticamente, as características dessas amostras geram um modelo matemático capaz de representar o comportamento imobiliário de uma localidade, minimizando a interferência especulativa e aleatoriedade nos padrões de compra e venda, proporcionando embasamento nas cobranças tributárias.

A inferência estatística através da técnica de regressão linear múltipla foi o procedimento utilizado para análise do Método Comparativo de Dados de Mercado. Os dados do mapeamento geométrico básico, do MDT e do cadastro imobiliário constituíram os elementos básicos para a elaboração do Modelo de Regressão Linear Convencional (MRLC). A qualidade de predição do MRLC foi avaliada de acordo com os pressupostos recomendados pela NBR 14.653-2 como a linearidade, normalidade, homocedasticidade, autocorrelação, multicolinearidade, pontos significantes e testes de significância, sendo adotado nesses procedimentos um nível de significância de 5\% (intervalo de confiança de 95\%). E o delineamento amostral foi norteado de acordo com a referida norma, que estabelece o número mínimo de amostras (n) em função da quantidade de variáveis independentes (k) (Equação 1):

$$
\mathrm{n}=4(k+1)
$$

A princípio foram consideradas 9 variáveis para compor o MRLC, sendo o Valor Venal (VV) representando a variável dependente (Tabela 1). A amostragem foi aleatória, de modo a contemplar uma ampla distribuição de imóveis, totalizando 235 observações. Os VV de cada amostra foram determinados em função do custo setorizado por $\mathrm{m}^{2}$, fixado pelo código tributário municipal para determinados setores da cidade. As variáveis preditoras do MRLC foram determinadas a partir de análises espaciais em SIG, pelas informações da base vetorial cartográfica e do cadastro imobiliário. E devido aos testes de significância do teste $\mathrm{F}$ (FisherSnedecor) através da análise de variância (ANOVA), a quantidade de variáveis independentes foi reduzida a 5. 
Tabela 1 - Variáveis utilizadas no MRLC.

\begin{tabular}{|c|c|c|c|c|}
\hline Categoria & Variável & Unidade/atributo & Peso & $\begin{array}{r}\text { p-valor (Teste } \\
\text { F) }\end{array}$ \\
\hline Variável dependente & Valor Venal & $\mathrm{R} \$$ & $\begin{array}{ll}--- \\
--\end{array}$ & 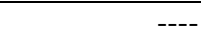 \\
\hline \multirow{3}{*}{$\begin{array}{l}\text { Variável independente } \\
\text { quantitativa }\end{array}$} & Área & $\mathrm{m}^{2}$ & ---- & 0,00000 \\
\hline & Declividade & $\begin{array}{c}\text { 1/declividade média do terreno de cada } \\
\text { imóvel }(\%)\end{array}$ & ---- & 0,00373 \\
\hline & Comércio & $\begin{array}{l}\text { 1/ distância mínima a rua de maior comércio } \\
\text { da cidade }(\mathrm{m})\end{array}$ & ---- & 0,00000 \\
\hline \multirow{5}{*}{$\begin{array}{l}\text { Variável independente } \\
\text { qualitativa }\end{array}$} & Utilização do imóvel & $\begin{array}{c}\text { Terreno sem uso } \\
\text { Residencial } \\
\text { Comércio de menor impacto } \\
\text { Comércio de maior impacto } \\
\end{array}$ & $\begin{array}{r}0,2 \\
0,4 \\
0,6 \\
1\end{array}$ & 0,93106 \\
\hline & Estado da construção & $\begin{array}{c}\text { Nova / Ótima } \\
\text { Bom } \\
\text { Regular } \\
\text { Ruim } \\
\end{array}$ & $\begin{array}{r}1 \\
0,6 \\
0,4 \\
0,2\end{array}$ & 0,00061 \\
\hline & Fachada & $\begin{array}{c}\text { Ausente } \\
\text { Reboco } \\
\text { Cerâmica }\end{array}$ & $\begin{array}{r}0,2 \\
0,6 \\
1\end{array}$ & 0,47261 \\
\hline & $\mathrm{N}^{\mathrm{o}}$ de pavimentos & $\begin{array}{c}\text { 1 Pavimento } \\
2 \text { Pavimentos } \\
3 \text { Pavimentos }\end{array}$ & $\begin{array}{r}0,2 \\
0,6 \\
1 \\
\end{array}$ & 0,00000 \\
\hline & Situação & $\begin{array}{l}\text { Lotes de meio de quadra } \\
\text { Lotes de esquina }\end{array}$ & $\begin{array}{r}0,2 \\
1\end{array}$ & 0,43250 \\
\hline
\end{tabular}

Fonte: Os autores (2021).

A variável área foi diretamente proporcional ao VV dos imóveis e é representada pela área total do terreno do imóvel (área construída e não construída). As variáveis declividade e comércio foram inversamente proporcionais ao VV dos imóveis. Esta última foi determinada a partir de análise direcionada a redes em ambiente SIG, na qual foram calculadas as distâncias mais curtas sob o eixo dos logradouros de cada imóvel em relação ao ponto central da principal rua de comércio da cidade. Os pesos das variáveis qualitativas foram atribuídos em função da importância de cada atributo e ordenados de modo que as diferenças entre os intervalos fossem equivalentes.

A escala original da série de dados de cada variável destoava-se muito de uma distribuição normal o que comprometeria a qualidade do MRLC. Assim, precedido dos testes de significância $F(p<0,05)$, foram realizadas transformações de Box-Cox e Johnson sob cada variável, de modo a proporcionar uma melhor aderência dos dados a uma distribuição normal (JOHNSON, 1949; YEO; JOHNSON, 2000). No caso da detecção de pontos atípicos, foram realizadas análises de diagramas de dispersão entre variáveis independentes e o VV além do diagnóstico de um MRLC preliminar, nos quais foram eliminados 31 outliers que poderiam enviesar o MRLC definitivo, o que proporcionou na redução das amostras em 204 observações (Figura 2). 
Figura 2 - Espacialização dos 204 elementos amostrais sob a área urbana do município de Itororó - BA.

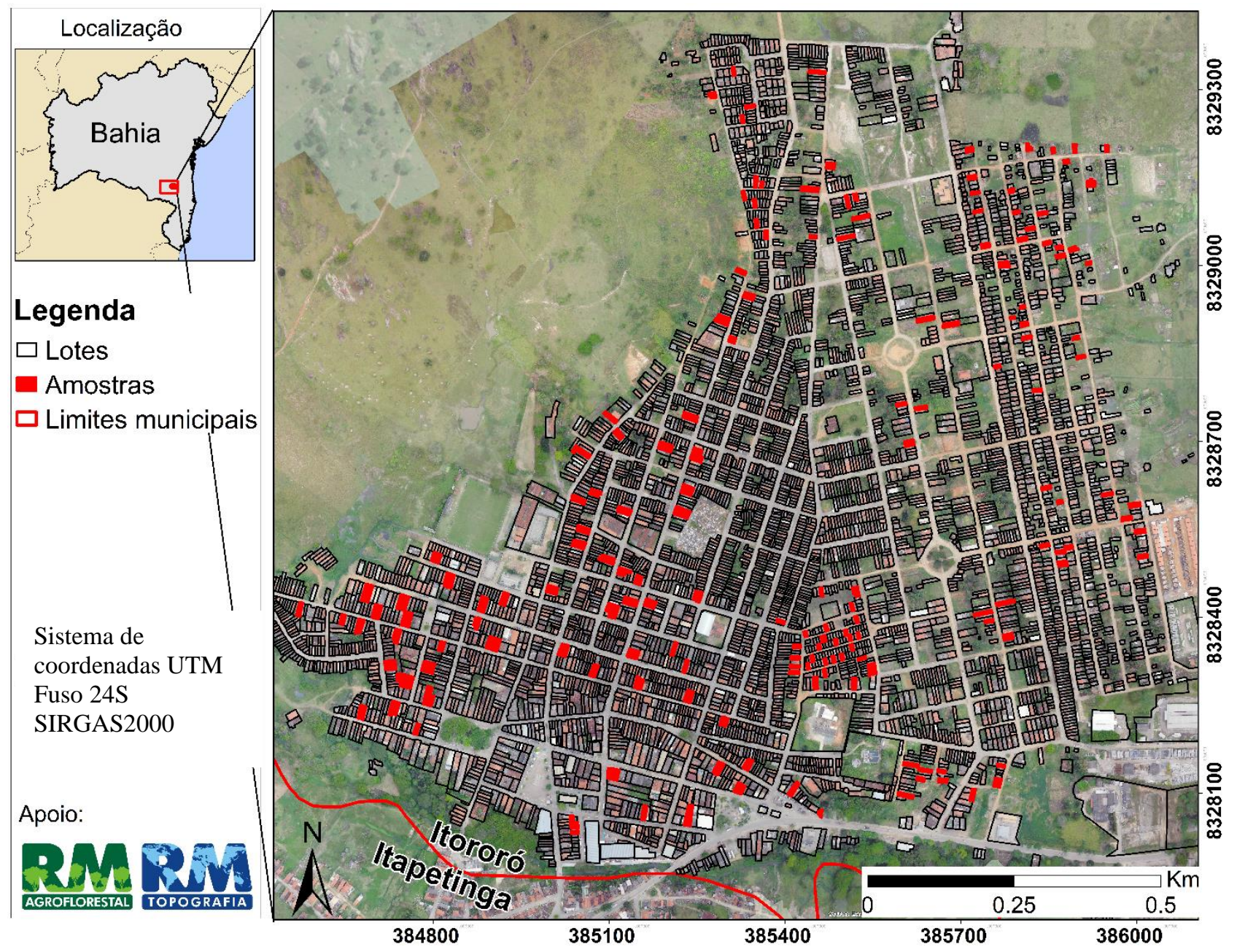

\subsection{Modelos de regressão espacial}

De acordo com Anselin (1988), dados espacialmente posicionados, como o caso da habitação, podem conter erros de medidas em relação à exata localização do imóvel, além dos efeitos de interação, difusão ou "spillovers" espaciais, de modo a ocasionarem dependência ou heterogeneidade espacial. A autocorrelação ou dependência espacial pode afetar tanto o termo de erro, a variável dependente, ou ambos, para isso foram desenvolvidos modelos matemáticos de regressão espaciais que incorporaram tanto os efeitos da autocorrelação nos resíduos (erros) mediante modelo do Erro espacial (Equação 2), quanto os efeitos da autocorreção na variável dependente, através do modelo de Defasagem espacial (Spatial Lag) (Equação 3):

$$
\begin{gathered}
\varepsilon=\lambda W \varepsilon+\mu \\
Y=X \beta+\rho W Y+\varepsilon
\end{gathered}
$$

sendo $\lambda$ e $\rho$ coeficientes de autocorrelação espacial do termo do erro e da variável espacialmente defasada respectivamente; $\mathrm{W}$ - matriz de pesos espaciais; $\mathcal{E}$ - resíduos do modelo; $\mu$ - resíduos não correlacionados; $\mathrm{X}$ - variáveis independentes; $\beta$ - parâmetros do modelo e $\mathrm{Y}$ - variável dependente.

A desconsideração desses efeitos pode gerar sérios problemas de estimação, pois, na presença de autocorrelação espacial tanto nos resíduos quanto nos preços imobiliários, os parâmetros estimados são ineficientes, com testes de significância como t de Student e F de Snedecor, e intervalos de confiança inválidos, e consequentemente as decisões tomadas com base neles são enganosas (DANTAS; MAGALHÃES; VERGOLINO, 2010).

Além disso, a verificação do tipo e intensidade da autocorrelação espacial da variável dependente, assim como da sua correlação com as variáveis explicativas, está diretamente relacionada à presença ou não de 
estacionariedade espacial (dependência espacial constante). Se o fenômeno em análise apresentar forte estacionariedade, modelos globais de regressão espacial, com coeficientes únicos para toda a área em estudo, serão capazes de descrever bem a relação observada de dependência espacial. Caso contrário, essa representação global pode comprometer a precisão das estimativas em alguns pontos, justificando-se a calibração de coeficientes específicos para diferentes regiões do espaço, implicando na estimativa de modelos locais de regressão espacial, destacando-se a regressão linear geograficamente ponderada (CARVALHO et al., 2006), expressa matematicamente na Equação 4.

$$
Y=\beta_{o}+\sum_{k=1}^{p} \beta_{k} \cdot X_{k, i}+\varepsilon_{i}
$$

sendo: $\beta_{0}$ - Intercepto global (constante); $\beta \mathrm{k}$ - k-ésimo coeficiente angular global referente a xk (constante); xk,i - k-ésima variável explicativa na localização i e $\mathcal{E}$ - erros independentes.

Para a elaboração dos modelos globais e locais de regressão espacial foi utilizada a mesma quantidade de amostras do MCRL, além das 8 variáveis independentes e o VV. O primeiro procedimento para elaboração dos modelos com efeitos espaciais globais foi a determinação de uma variável homogeneizada que incorporasse o fator da localização do imóvel em detrimento da ausência do efeito de todas as variáveis relacionadas as características construtivas dos imóveis. Esse método proposto por Trivelloni (2005) consistiu na divisão do valor venal pelos fatores de homogeneização que representam os coeficientes determinados pelo método dos mínimos quadrados do MCRL. Posteriormente foi gerada uma matriz de pesos espaciais (W) que considerou o alcance do semivariograma da variável homogeneizada, como a distância máxima para que dois imóveis fossem considerados vizinhos (1.200,78 m) e consequentemente recebessem peso 1.

Em seguida, através de dois novos MRLC (um com 7 e outro com as 9 variáveis) e a matriz W, foi avaliada por meio dos testes de Multiplicador de Lagrange (LM) robusto da defasagem espacial e do erro, a autocorrelação espacial dos resíduos e da variável independente dos dois novos modelos clássicos gerados. Para construção dos modelos espaciais locais foi considerada uma função de ponderação (kernel) biquadrática cuja variância é subordinada a uma largura de banda definida nesse procedimento como adaptativa, testada pelo critério de seção Golden. A análise da adequação dos modelos espaciais foi realizada mediante valor da probabilidade ao nível significância de $95 \%(\mathrm{p}<0,05)$ dos 2 testes LM e pelos critérios de informação de Akaike.

\subsection{Análise do desempenho dos modelos de regressão}

O desempenho dos modelos de regressão múltipla selecionados (clássico e espaciais) foi avaliado através do percentual de erro relacionado a diferença entre o valor observado e estimado pelos modelos de regressão (Equação 5) (GAZOLA, 2002; FILHO; BRITO; GONÇALVES, 2017) e pelo Coeficiente de Dispersão (COD), recomendado pela Association of Assessing Officers (IAAO, 2013), cuja Equação 6 foi adaptada de Filho, Brito e Gonçalves (2017).

$$
\begin{gathered}
\text { Erro }(\%)=\left[\frac{\left(\mathrm{VV}_{\text {obs }}-\mathrm{VV}_{\text {est }}\right)}{\mathrm{VV}_{\text {obs }}}\right] * 100 \\
\operatorname{COD}(\%)=\left[\frac{\text { Média }\left(\frac{\mathrm{V} \mathrm{V}_{\text {est }}}{\mathrm{VV}_{\text {obs }}}\right)-\text { Mediana }\left(\frac{\mathrm{VV} \text { est }}{\mathrm{VV}_{\text {obs }}}\right)}{\text { Mediana }\left(\frac{\mathrm{VV}_{\text {est }}}{\mathrm{VV}_{\text {obs }}}\right)}\right] * 100
\end{gathered}
$$

considerando-se: VVest - Valor Venal estimado pelo modelo de regressão múltipla (convencional e espacial) e VVobs - Valor Venal observado. 


\section{RESULTADOS}

\subsection{Modelo de Regressão Linear Convencional}

De maneira geral, os pressupostos básicos para garantia da qualidade do modelo foram satisfeitos, os testes de colinearidade e multicolinearidade indicaram a independência entre as variáveis do MRLC. A matriz de correlações apontou uma correlação máxima de 0,29 , muito inferior ao limite máximo estabelecido pela NBR 14653-2 de 0,80 e no caso da multicolinearidade, os fatores de inflação da variância (VIF) foram inferiores a 10 indicando a ausência desse problema (Tabela 2). O coeficiente de determinação $\left(\mathrm{R}^{2}\right)$ indicou que $89 \%$ da variabilidade dos dados foi explicada pelo MRLC. Como já apontado antes, os resultados dos testes de significância $\mathrm{F}$ e $\mathrm{t}$ dos coeficientes do modelo rejeitaram a hipótese nula, apontando que o intercepto e as variáveis de entrada foram importantes para o modelo (Tabela 3).

Tabela 2 - Matriz de correlação para análise da colinearidade e fator de inflação da variância (VIF) para análise de multicolinearidade.

\begin{tabular}{l|rrrrr}
\hline & Área & Estado da construção & Declividade & Pavimentos & Comércio \\
\hline Área & 1,00 & $-0,31$ & 0,10 & 0,23 & 0,18 \\
Estado da construção & $-0,31$ & 1,00 & $-0,07$ & $-0,31$ & $-0,25$ \\
Declividade & 0,10 & $-0,07$ & 1,00 & 0,18 & $-0,06$ \\
Pavimentos & 0,23 & $-0,31$ & 0,18 & 1,00 & 0,29 \\
Comércio & 0,18 & $-0,25$ & $-0,06$ & 0,29 & 1,00 \\
\hline VIF & 1,143 & 1,215 & 1,056 & 1,228 & 1,153 \\
\hline
\end{tabular}

Fonte: Os autores (2021).

Tabela 3 - Testes de significância das variáveis e dos coeficientes e parâmetros do MRLC. ( $\sigma$ - Desvio Padrão).

\begin{tabular}{|c|c|c|c|c|c|c|}
\hline Variáveis & Estatística $\mathbf{F}$ & p-valor & Coeficientes & $\sigma$ (Coeficientes) & Est. t & p-valor \\
\hline Área & 1030,87 & 0,00000000 & 0,6137 & 0,0262 & 23,4548 & 0,00000000 \\
\hline Estado da const. & 100,21 & 0,00000000 & $-0,2398$ & 0,0688 & $-3,4835$ & 0,00060916 \\
\hline Declividade & 18,17 & 0,00003131 & 0,0826 & 0,0281 & 2,9352 & 0,00372749 \\
\hline Pavimentos & 273,83 & 0,00000000 & 0,0400 & 0,0030 & 13,4481 & 0,00000000 \\
\hline Comércio & 125,26 & 0,00000000 & 0,2770 & 0,0247 & 11,1920 & 0,00000000 \\
\hline Intercepto & & & 0,4768 & 0,0908 & 5,2490 & 0,00000039 \\
\hline \multicolumn{7}{|c|}{ Medida Descritiva da Qualidade do Ajuste } \\
\hline $\begin{array}{c}\boldsymbol{\sigma} \text { (Resíduos) } \\
0,3261\end{array}$ & $\begin{array}{c}\mathbf{R}^{\mathbf{2}} \\
0,8866\end{array}$ & tado & & & & \\
\hline
\end{tabular}

Fonte: Os autores (2021).

Os resultados dos testes de normalidade indicaram aderência dos resíduos a uma distribuição normal, rejeitando a hipótese alternativa $\left(\mathrm{H}_{1}, \mathrm{p}>0,05\right)$ (Tabela 4). Os critérios de normalidade e linearidade foram satisfeitos mediante análise do gráfico de distribuição da probabilidade normal, através da aderência dos resíduos em relação a reta de normalidade, além da tendência à simetria do histograma e, consequentemente, da função densidade da normal (Figura 3). A NBR 14.653-2 ressalta que a normalidade dos resíduos também é indicada pela plotagem dos resíduos padronizados versus valores ajustados dispostos aleatoriamente com a grande maioria dos dados situados no intervalo $[-2 ;+2]$, conforme o gráfico da Figura 3.

Tabela 4 - Testes de normalidade dos resíduos do MRLC.

\begin{tabular}{c|cc}
\hline Teste de normalidade & Estatística & p-valor \\
\hline Anderson-Darling & 0,626758193 & 0,101220921 \\
Kolmogorov-Smirnov & 0,048747523 & 0,278792505 \\
Ryan-Joiner & 0,994463869 & 0,1046 \\
\hline
\end{tabular}

Fonte: Os autores (2021). 
Figura 2 - Histograma, quantis da normal e diagrama de dispersão dos resíduos do MRLC.
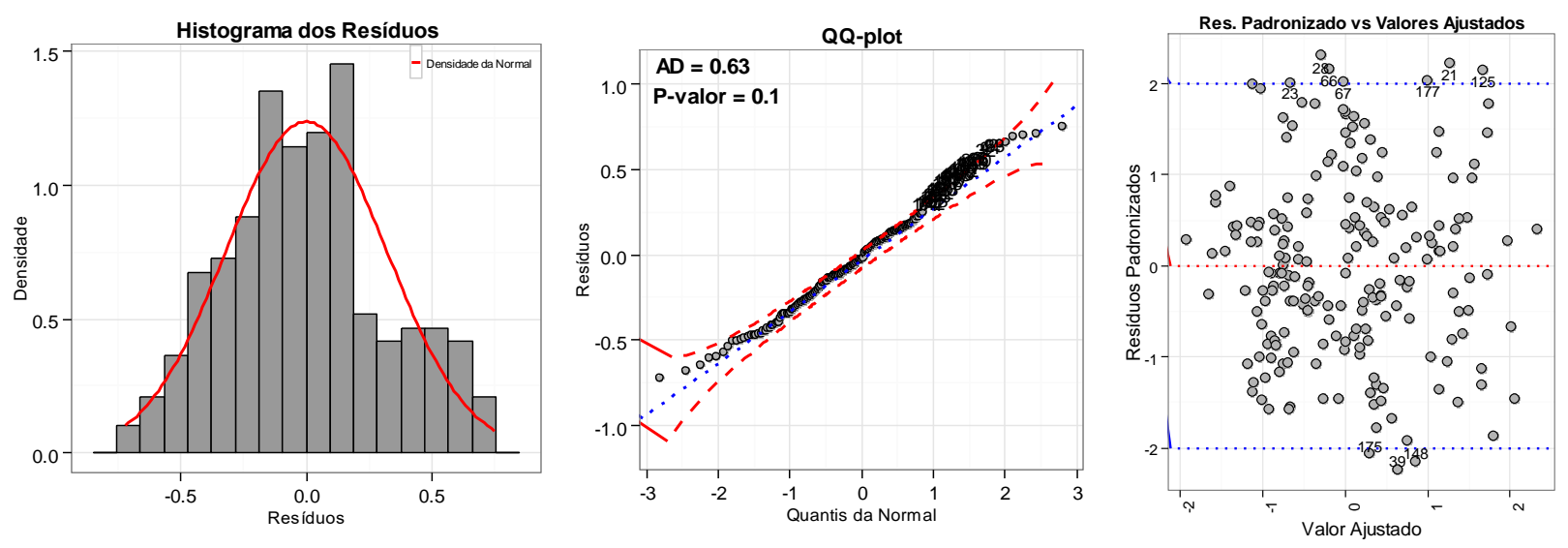

Fonte: Os autores (2021).

De modo geral, os pressupostos de homocedasticidade e autocorrelação dos erros foram satisfeitos através dos testes da Tabela 5. De acordo com o teste global de Breusch Pagan a variabilidade dos resíduos do modelo é considerada constante ( $p>0,05)$, não descartando a hipótese nula de constância das variâncias dos resíduos $\left(\mathrm{H}_{0}\right)$. O mesmo resultado se mantém para os casos individuais, em que todas as variáveis independentes exceto a variável Comércio apresentaram a condição de homocedasticidade para seus resíduos. No caso da avaliação da ausência de autocorrelação dos erros através do teste de Durbin-Watson, o resultado foi semelhante aos testes anteriores, indicando independência dos resíduos ( $p>0,05)$.

Tabela 5 - Testes de homocedasticidade dos resíduos e das variáveis independentes e teste da ausência de autocorrelação dos erros do MRLC.

\begin{tabular}{|c|c|c|}
\hline \multicolumn{3}{|c|}{ Teste de Homocedasticidade - Breusch Pagan } \\
\hline Estatística & & p-valor \\
\hline 2,865 & & 0,0905 \\
\hline \multicolumn{3}{|c|}{ Teste de Homocedasticidade - Goldfeld Quandt } \\
\hline Variável & Estatística & p-valor \\
\hline Área & 1,449 & 0,05473 \\
\hline Estado da construção & 0,725 & 0,91768 \\
\hline Declividade & 0,838 & 0,77742 \\
\hline Pavimentos & 0,882 & 0,70730 \\
\hline Comércio & 1,945 & 0,00217 \\
\hline \multicolumn{3}{|c|}{ Teste de Independência - Durbin-Watson } \\
\hline Estatística & & p-valor \\
\hline 1,960 & & 0,3619 \\
\hline
\end{tabular}

Fonte: Os autores (2021).

\subsection{Modelos de Regressão Espacial (Globais e Locais)}

Foram gerados 4 modelos espaciais de regressão múltipla com efeito espacial global, sendo dois modelos espaciais da componente erro e dois modelos espaciais da defasagem (cada par de modelo com 7 e 9 variáveis no total). De acordo com os testes multiplicador de Lagrange Robusto do erro e da defasagem espacial ( $\mathrm{Lag}$ ), os modelos apresentaram efeito de autocorrelação espacial apenas para a defasagem espacial $(\mathrm{p}<0,05)$. Quanto aos testes de normalidade dos resíduos, os resultados indicaram aderência a uma distribuição normal para a maioria dos testes, sobretudo quanto aos modelos da defasagem espacial. Além disso, o teste de homocedasticidade indicou variabilidade constante dos resíduos dos 4 modelos ( $>0,05)$ (Tabela 6). No caso da adequação do tipo de modelo, o modelo com 7 variáveis além de apresentar menor nível de significância para o efeito da defasagem espacial do VV do que o modelo com 9 varáveis, também obteve menor valor para o critério de informação de Akaike $(124,160)$.

Com relação ao desempenho dos coeficientes estimados nos 4 modelos de regressão espaciais global (Tabela 7), infere-se que de maneira geral os modelos apresentaram poucas diferenças entre os coeficientes das variáveis independentes, os níveis de significância e erros padrão. As diferenças tornam-se mais perceptíveis comparando-se os modelos com 9 e 7 variáveis. Nos modelos com 9 variáveis, os níveis de 
significância foram mais altos para as variáveis Fachada e Utilização ( $\mathrm{p}>0,05)$, proporcionando maiores margem de erro em relação aos modelos mais reduzidos (7 variáveis).

Tabela 6 - Testes autocorrelação espacial da defasagem espacial (lag) e do erro, parâmetros e critérios dos modelos de regressão espacial globais, testes de normalidade e homocedasticidade dos resíduos. Lag - Defasagem espacial; Est. Estatística do teste; $\rho$ (Rhô) - Coeficiente de autocorrelação espacial da variável dependente; $\lambda$ (Lambda) - Coeficiente de autocorrelação espacial do termo do erro; Log Ver. - Log Verossimilhança e N/A - Não se Aplica; Valores em negrito indicam nível de significância $(\mathrm{p}<0,05)$.

\begin{tabular}{|c|c|c|c|c|c|c|c|c|c|c|c|c|}
\hline \multirow{2}{*}{ Modelos espaciais } & \multicolumn{2}{|c|}{ LM robusto (lag) } & \multicolumn{2}{|c|}{ LM robusto (erro) } & \multicolumn{5}{|c|}{ Parâmetros do modelo } & \multicolumn{3}{|c|}{ Critérios } \\
\hline & Est. & p-valor & Est. & p-valor & \multirow{2}{*}{\multicolumn{2}{|c|}{$\rho$}} & \multirow{2}{*}{$\lambda$} & \multicolumn{2}{|c|}{$\mathbf{R}^{2}$} & Log Ver. & Akaike & Schwarz \\
\hline Lag (7 variáveis) & 6,79 & 0,009 & \multicolumn{2}{|c|}{ N/A } & & & & & 391 & $-54,705$ & 124,160 & 150,705 \\
\hline Lag (9 variáveis) & 6,63 & 0,010 & \multicolumn{2}{|c|}{ N/A } & \multicolumn{2}{|c|}{0,475} & N/A & \multicolumn{2}{|c|}{0.893} & $-52,372$ & 124,745 & 157,926 \\
\hline Erro (7 variáveis) & \multicolumn{2}{|c|}{ N/A } & 2,258 & 0,133 & $\mathrm{~N}$ & & $-0,341$ & & 389 & $-55,750$ & 125,500 & 148,727 \\
\hline Erro $(9 \mathrm{v}$ & & 2,139 & 0,144 & $\mathrm{~N} /$ & & $-0,300$ & & 391 & $-54,040$ & 126,080 & 155,943 \\
\hline \multirow{3}{*}{ Modelos espaciais } & \multicolumn{10}{|c|}{ Testes de Normalidade } & \multicolumn{2}{|c|}{$\begin{array}{c}\text { Teste de } \\
\text { Homocedasticidade }\end{array}$} \\
\hline & \multicolumn{2}{|c|}{ Anderson-Darling } & \multicolumn{3}{|c|}{ Kolmogorov-Smirnov } & \multicolumn{3}{|c|}{ Shapiro-Wilk } & \multicolumn{2}{|c|}{ Ryan - Joiner } & \multicolumn{2}{|c|}{ Breusch-Pagan } \\
\hline & Est. & p-valor & Est. & p-valo & & Est. & p-val & & Est & p-valor & Est. & p-valor \\
\hline Lag (7 variáveis) & 0,516 & 0,1890 & 0,038 & 0,6 & & 0,98 & 0,06 & & 0,99 & 0,1479 & 7,192 & 0,303 \\
\hline Lag (9 variáveis) & 0,532 & 0,1713 & 0,048 & 0,2 & & 0,98 & 0,05 & & 0,99 & 0,1329 & 7,540 & 0,480 \\
\hline Erro (7 variáeis) & 0,752 & 0,0496 & 0,058 & 0,0 & & 0,98 & $\mathbf{0 , 0 1}$ & & 0,99 & 0,0501 & 7,366 & 0,288 \\
\hline Erro (9 variáeis) & 0,751 & 0,0497 & 0,055 & & & 0,98 & 0,01 & & 0,99 & 0,0519 & 7,917 & 0,442 \\
\hline
\end{tabular}

Fonte: Os autores (2021).

Tabela 7 - Coeficientes e demais parâmetros das variáveis dos 4 modelos de regressão espacial globais. Coef. Coeficientes das variáveis do modelo; EP - Erro Padrão da variável do modelo; Valores em negrito indicam nível de significância $(\mathrm{p}<0,05)$.

\begin{tabular}{|c|c|c|c|c|c|c|c|c|}
\hline \multirow{2}{*}{ Modelos com 9 variáveis } & \multicolumn{4}{|c|}{ Modelo da defasagem (Lag) } & \multicolumn{4}{|c|}{ Modelo do erro } \\
\hline & Coef. & EP & Estatística t & p-valor & Coef. & EP & Estatística t & p-valor \\
\hline Valor Venal & 0,475 & 0,250 & 1,900 & 0,0574 & \multicolumn{4}{|c|}{ N/A } \\
\hline Área & 0,614 & 0,025 & 24,271 & $\mathbf{0 , 0 0 0 0 0}$ & 0,616 & 0,025 & 24,160 & 0,00000 \\
\hline Estado da construção & $-0,206$ & 0,067 & $-3,062$ & 0,00220 & $-0,227$ & 0,067 & $-3,372$ & 0,00075 \\
\hline Declividade & 0,093 & 0,027 & 3,393 & 0,00069 & $\mathbf{0 , 0 8 0}$ & $\mathbf{0 , 0 2 7}$ & 2,920 & 0,00350 \\
\hline Pavimentos & 0,040 & 0,003 & 13,850 & 0,00000 & 0,040 & $\mathbf{0 , 0 0 3}$ & 13,915 & 0,00000 \\
\hline Comércio & 0,267 & 0,026 & 10,444 & 0,00000 & 0,291 & 0,024 & 11,943 & 0,00000 \\
\hline Fachada & 0,084 & 0,093 & 0,895 & 0,37056 & 0,065 & 0,094 & 0,694 & 0,48787 \\
\hline Utilização & 0,131 & 0,085 & 1,552 & 0,12061 & 0,143 & 0,085 & 1,670 & 0,09487 \\
\hline Situação & 0,009 & 0,004 & 2,175 & 0,02966 & 0,008 & 0,004 & 2,069 & $\mathbf{0 , 0 3 8 5 8}$ \\
\hline Intercepto & $\mathbf{0 , 8 8 8}$ & 0,174 & 5,095 & 0,00000 & 0,876 & 0,176 & 4,988 & $\mathbf{0 , 0 0 0 0 0}$ \\
\hline$\lambda$ & & & N/A & & $-0,300$ & 0,875 & $-0,342$ & 0,73203 \\
\hline \multirow{2}{*}{ Modelos com 7 variáveis } & \multicolumn{4}{|c|}{ Modelo da defasagem (Lag) } & \multicolumn{4}{|c|}{ Modelo do erro } \\
\hline & Coef. & EP & Estatística t & p-valor & Coef. & EP & Estatística t & p-valor \\
\hline Valor Venal & 0,477 & 0,250 & 1,911 & 0,05600 & \multicolumn{4}{|c|}{ N/A } \\
\hline Área & 0,613 & 0,025 & 24,191 & 0,00000 & 0,615 & 0,026 & 24,022 & 0,00000 \\
\hline Estado da construção & $-0,218$ & 0,067 & $-3,245$ & 0,00118 & $-0,242$ & 0,067 & $-3,598$ & $\mathbf{0 , 0 0 0 3 2}$ \\
\hline Declividade & 0,094 & $\mathbf{0 , 0 2 7}$ & 3,426 & 0,00061 & $\mathbf{0 , 0 8 0}$ & 0,028 & 2,913 & 0,00358 \\
\hline Pavimentos & 0,040 & $\mathbf{0 , 0 0 3}$ & 13,832 & 0,00000 & 0,040 & $\mathbf{0 , 0 0 3}$ & 13,900 & 0,00000 \\
\hline Comércio & 0,266 & 0,026 & 10,339 & 0,00000 & 0,291 & 0,024 & 11,874 & 0,00000 \\
\hline Situação & 0,008 & 0,004 & 2,104 & 0,03541 & 0,008 & 0,004 & 2,011 & 0,04432 \\
\hline Intercepto & 0,667 & 0,122 & 5,445 & 0,00000 & 0,644 & 0,123 & 5,252 & 0,00000 \\
\hline$\lambda$ & & & N/A & & $-0,341$ & 0,901 & $-0,380$ & 0,70460 \\
\hline
\end{tabular}

Fonte: Os autores (2021).

Da mesma forma que os modelos espaciais globais, foram gerados dois modelos locais de Regressão Geograficamente Ponderada (RGP) com as mesmas variáveis. Observa-se que através dos parâmetros da RGP (Tabela 8), ambos os modelos proporcionaram boas medidas de ajuste para os dados em relação aos modelos globais da defasagem e da componente erro. As análises entre os dois modelos de regressão locais (RGP) indicaram que o modelo com 7 variáveis apresentou melhor performance para as estimativas do VV dos imóveis da cidade de Itororó, esse modelo conseguiu explicar a quase totalidade da variação dos preços imobiliários (cerca de $98 \%$ ), além do valor obtido para o critério AICc ser o mais inferior $(-57,962)$ e a largura de banda $(54 \mathrm{~km})$, indicando maior densidade de dados e portanto menores observações locais para estimar a variável dependente.

Ao contrário dos modelos regressão com efeitos espaciais globais, os testes de normalidade não indicaram aderência dos resíduos a uma distribuição normal. No entanto, a distribuição aleatória desses 
resíduos com os valores ajustados no diagrama de dispersão pode sugerir variabilidade constante e, portanto, condição de homocedasticidade de ambos os modelos de RGP, reforçado pelo fato dos coeficientes de correlação baixos e não significativos (Pearson=0,02, p>0,05 para ambos) (Figura 4). Em relação as estatísticas descritivas dos coeficientes entre os dois modelos (Tabela 9), o desvio padrão médio do modelo com 7 variáveis foi menor $(0,130)$ em relação ao primeiro modelo $(1,128)$, representando uma diferença de cerca de 9 unidades e indicando menor viés do modelo mais reduzido.

Tabela 8 - Parâmetros dos modelos de RGP.

\begin{tabular}{|c|c|c|c|c|c|c|c|c|}
\hline \multirow{2}{*}{ Modelos espaciais } & \multicolumn{5}{|c|}{ Parâmetros do modelo } & & & \\
\hline & $\mathbf{R}^{2}$ & $\mathbf{R}^{2}$ ajustado & Bandwidth & AICc & Estatística $\mathbf{F}$ & & & \\
\hline 9 variáveis & 0,972 & 0,959 & 71,16 & $-27,772$ & 7,530 & & & \\
\hline 7 variáveis & 0,976 & 0,965 & 54,00 & $-57,962$ & 9,160 & & & \\
\hline \multicolumn{9}{|c|}{ Testes de Normalidade } \\
\hline \multirow{2}{*}{ Modelos espaciais } & \multirow{2}{*}{\multicolumn{2}{|c|}{$\begin{array}{l}\text { Anderson-Darling } \\
\text { Est. p-valor }\end{array}$}} & \multicolumn{2}{|c|}{ Kolmogorov-Smirnov } & \multicolumn{2}{|c|}{ Shapiro-Wilk } & \multicolumn{2}{|c|}{ Ryan - Joiner } \\
\hline & & & Est. & p-valor & Est. & p-valor & Est. & p-valor \\
\hline 9 variáveis & 2,038 & 0 & 0,074 & 0,008 & 0,955 & 0,000 & 0,97394 & 0 \\
\hline 7 variáveis & 1,292 & 0,002 & 0,072 & 0,011 & 0,977 & 0,002 & 0,986872 & 0,001 \\
\hline
\end{tabular}

Fonte: Os autores (2021).

Figura 4 - Diagrama de dispersão dos resíduos versus valores padronizados dos modelos de RGP.
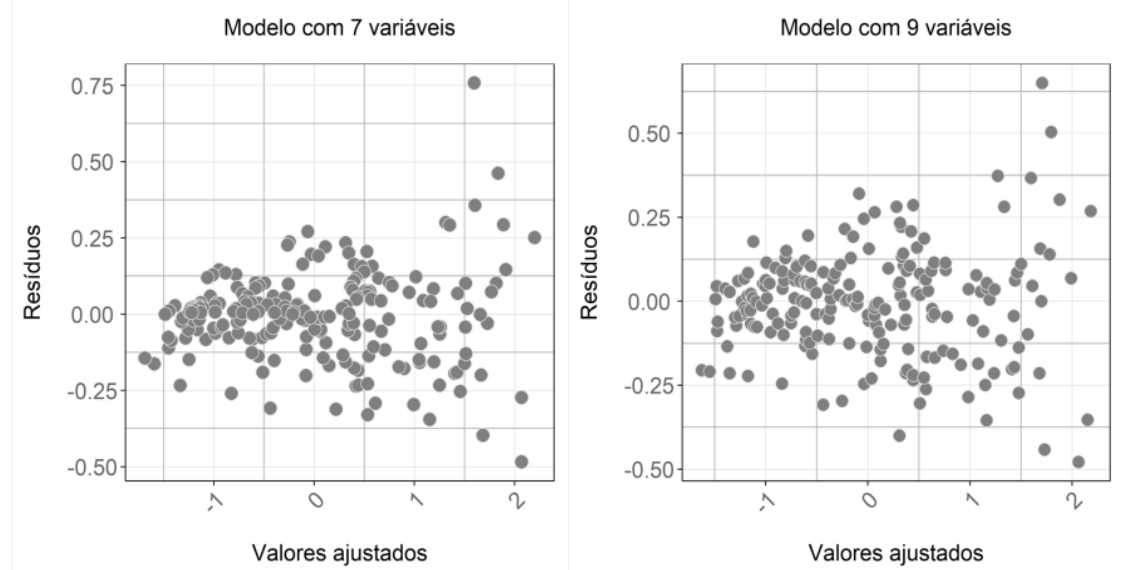

Fonte: Os autores (2021).

Tabela 9 - Estatísticas descritivas dos coeficientes das variáveis independentes e intercepto dos modelos de RGP.

\begin{tabular}{c|rrrrrrrc}
\hline Modelos espaciais & \multicolumn{7}{|c}{ Regressão Geograficamente Ponderada } \\
\hline Modelo com 9 variáveis & \multicolumn{1}{|c}{ Mín. } & Max. & Amplitude & Média & Mediana & $\mathbf{1}^{\mathbf{0}}$ Quartil & $\mathbf{3}^{\mathbf{0}}$ Quartil & $\boldsymbol{\sigma}$ \\
\hline Área & 0,414 & 0,646 & 0,232 & 0,509 & 0,495 & 0,463 & 0,569 & 0,063 \\
Estado da construção & $-0,248$ & 0,187 & 0,435 & $-0,001$ & 0,007 & $-0,056$ & 0,052 & 0,086 \\
Declividade & $-0,130$ & 0,185 & 0,315 & 0,014 & $-0,003$ & $-0,068$ & 0,084 & 0,080 \\
Pavimentos & 0,030 & 0,047 & 0,016 & 0,039 & 0,039 & 0,037 & 0,042 & 0,004 \\
Comércio & $-0,148$ & 0,619 & 0,768 & 0,235 & 0,152 & 0,021 & 0,492 & 0,240 \\
Fachada & $-0,331$ & 0,510 & 0,841 & 0,048 & 0,010 & $-0,025$ & 0,146 & 0,164 \\
Utilização & $-0,142$ & 0,344 & 0,486 & 0,061 & 0,032 & $-0,007$ & 0,148 & 0,099 \\
Situação & $-0,010$ & 0,026 & 0,037 & 0,008 & 0,006 & 0,003 & 0,012 & 0,008 \\
Intercepto & 0,142 & 1,616 & 1,474 & 0,915 & 0,914 & 0,637 & 1,248 & 0,384 \\
\hline Modelo com 7 variáveis & Mín. & Max. & Amplitude & Média & Mediana & $\mathbf{1}^{\mathbf{0}}$ Quartil & $\mathbf{3}^{\mathbf{0}}$ Quartil & $\boldsymbol{\sigma}$ \\
\hline Área & 0,394 & 0,641 & 0,246 & 0,492 & 0,493 & 0,438 & 0,541 & 0,057 \\
Estado da construção & $-0,191$ & 0,212 & 0,403 & $-0,024$ & $-0,038$ & $-0,095$ & 0,041 & 0,091 \\
Declividade & $-0,134$ & 0,237 & 0,371 & 0,016 & $-0,010$ & $-0,051$ & 0,093 & 0,091 \\
Pavimentos & 0,027 & 0,055 & 0,028 & 0,039 & 0,040 & 0,037 & 0,043 & 0,005 \\
Comércio & $-0,445$ & 0,710 & 1,155 & 0,197 & 0,181 & $-0,058$ & 0,465 & 0,288 \\
Situação & $-0,017$ & 0,031 & 0,048 & 0,006 & 0,003 & 0,001 & 0,011 & 0,011 \\
Intercepto & 0,075 & 1,416 & 1,340 & 0,727 & 0,768 & 0,474 & 0,991 & 0,368 \\
\hline
\end{tabular}

Fonte: Os autores (2021).

\subsection{Análise do desempenho dos modelos de regressão}

Para fins de comparação, além do modelo convencional (MCRL), foram selecionados dois modelos de regressão espaciais (um com efeito espacial global e outro com efeito espacial local), sendo o modelo da defasagem espacial (Spatial Lag) com 7 variáveis, em virtude de apresentar o menor nível de significância 
para efeito da autocorrelação espacial da variável dependente, menor valor para critério de Akaike e, portanto, valor superior de coeficiente de determinação $\left(\mathrm{R}^{2}\right)$. No caso do modelo com efeito espacial local, o modelo de RGP com 7 variáveis foi selecionado, também em razão dos dois últimos critérios apontados para o modelo da defasagem espacial (critério de Akaike e $\mathrm{R}^{2}$ ).

A análise do desempenho desses três modelos indicou que os modelos espaciais apresentaram menores erros e menor variabilidade dos valores preditos (Tabela 10). Sobretudo para o modelo de RGP em que a quantidade de amostras com erros inferiores a $20 \%$ representou aproximadamente $83 \%$, sendo o erro considerado máximo de $38 \%$ (valor máximo não outlier). No caso dos valores do Coeficiente de Dispersão (COD), apesar do melhor desempenho para o percentual de erro do modelo Spatial Lag em relação ao MRLC, o valor do COD foi ligeiramente maior $(15,07 \%)$, e o menor valor de COD foi obtido para o modelo de RGP $(3,89)$, quantidade cerca de 4 vezes inferior aos COD obtidos pelos outros dois modelos.

Tabela 10 - Métodos de desempenho dos modelos de regressão múltipla selecionados. (*) A diferença entre os valores totais de 204 observações foi resultado da desconsideração de outliers para cada modelo.

\begin{tabular}{|c|c|c|c|c|c|c|}
\hline Método de desempenho & \multicolumn{2}{|c|}{ MRLC } & \multicolumn{2}{|c|}{ Modelo Spatial Lag (7 Var) } & \multicolumn{2}{|c|}{ RGP (7 Var) } \\
\hline Percentual de Erro & $\mathrm{N}^{\circ}$ de amostras & $\%$ & $\mathrm{~N}^{\circ}$ de amostras & $\%$ & $\mathrm{~N}^{\circ}$ de amostras & $\%$ \\
\hline$<20 \%$ & 97 & 49,74 & 99 & 50,51 & 160 & 82,90 \\
\hline$<50 \%$ & 175 & 89,74 & 177 & 90,31 & 193 & 100,00 \\
\hline Total & $195 *$ & 100,00 & $196 *$ & 100,00 & $193 *$ & 100,00 \\
\hline $\operatorname{COD}(\%)$ & 14,04 & & 15,07 & & 3,89 & \\
\hline
\end{tabular}

Fonte: Os autores (2021).

Diante dos critérios de desempenho avaliados, o modelo de RGP com 7 variáveis foi o mais adequado para estimar o valor venal dos imóveis da cidade de Itororó. Assim, esse modelo foi extrapolado para um total de 5.169 imóveis que compuseram o mapeamento geométrico cadastral do município (Figura 5), e os valores venais dos imóveis foram corrigidos pelo Índice Geral de Preços (IGP-DI) para o mês setembro de 2019. Desse modo os valores variaram de $\mathrm{R} \$ 5.566,30$ a 539.146,65 (média de $\mathrm{R} \$ 17.430,96$ ). O código tributário municipal prevê uma alíquota de $0,15 \%$ sobre o valor venal para fins de arrecadação através do IPTU, sendo assim, foram calculados os valores desse imposto de acordo com os valores venais corrigidos. A arrecadação total seria de $\mathrm{R}$ \$ 135.150,98, no entanto considerando a isenção desse imposto para os imóveis com valor venal inferior a $\mathrm{R} \$ 20.000$, a arrecadação total reduziria para $\mathrm{R} \$ 96.859,94$. Criando-se um cenário hipotético em que a alíquota passasse a ser de $1 \%$ e também considerando-se a hipótese de isenção do IPTU, a arrecadação total aumentaria para $\mathrm{R} \$ 645.732,95$, crescimento de $567 \%$ em relação a arrecadação total com alíquota $0,15 \%$. 
Figura 5 - Planta de Valores Genéricos totais obtida pela extrapolação do modelo RGP (7 variáveis). Valores corrigidos pelo IGP-DI para setembro de 2019.

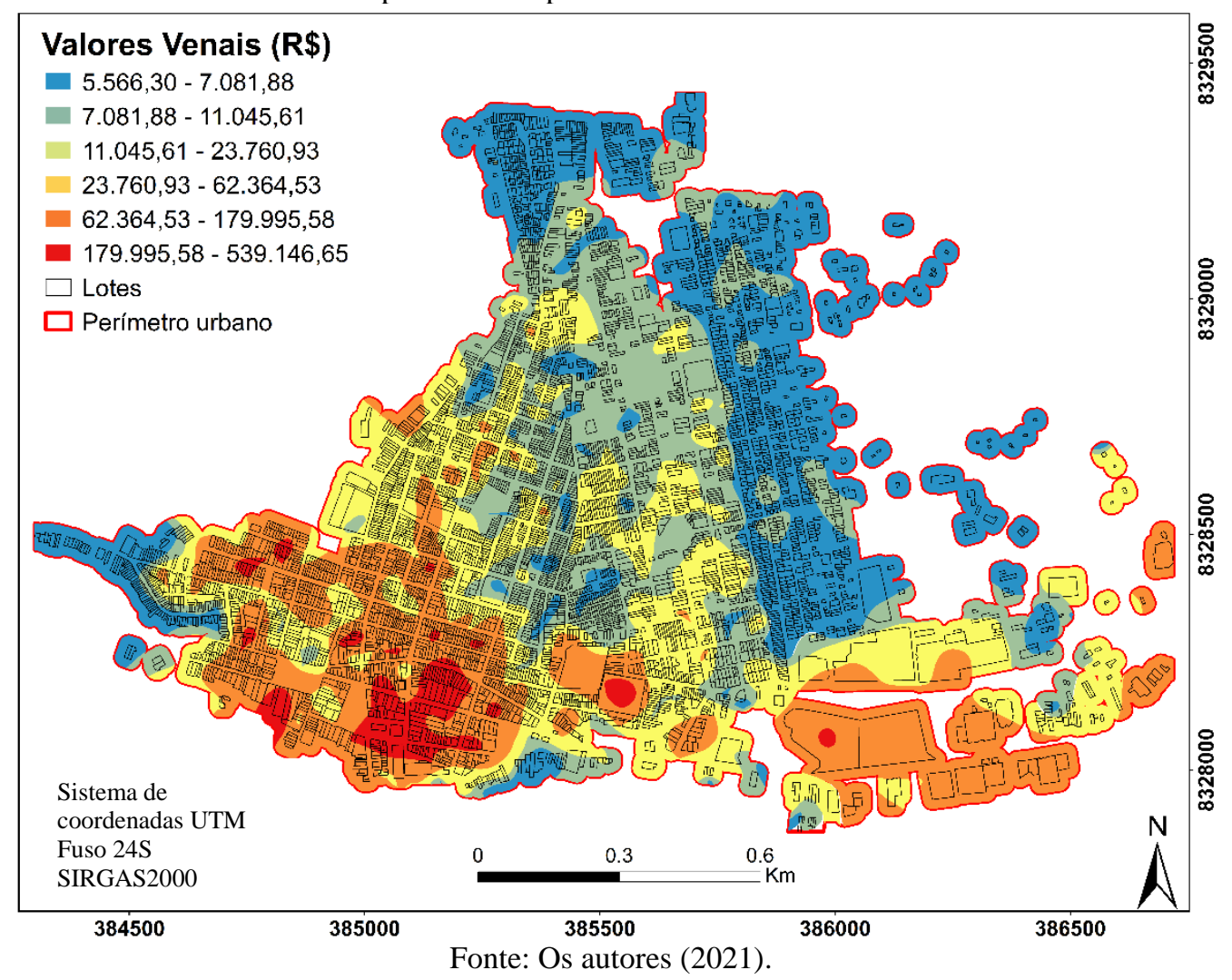

\section{DISCUSSÃO}

De maneira geral o MRLC atendeu todos os pressupostos básicos para garantia de sua qualidade, tal modelo conseguiu realizar uma boa predição dos preços imobiliários da cidade de Itororó em função do conjunto das variáveis independentes. Os valores positivos dos coeficientes indicaram que os valores venais foram diretamente proporcionais ao tamanho e ao inverso da declividade do terreno, ao número de pavimentos e a proximidade com a principal zona comercial do município. O resultado do bom desempenho do MRLC, sobretudo quanto a normalidade dos resíduos e autocorrelação dos erros, se devem principalmente as transformações dos dados originais, com intuito de proporcionar uma melhor aderência deles a uma distribuição normal. As transformações de Box-Cox foram complementadas pela transformação de Johnson já que a primeira só é utilizada com valores positivos. Esse tipo de transformação proporcionou eficiência no modelo de regressão convencional gerado para elaboração de uma PVG do município de Álvares Machado (SP), em que o erro na estimativa do valor do metro linear de testada corrigida pela regressão oriunda dos dados com distribuição normal foi $30 \%$ menor comparado à regressão gerada pelas amostras sem normalidade (OLIVEIRA et al., 2016).

Entretanto a performance do modelo clássico por si só não garante a qualidade de predição e nem confidencialidade dos valores dos imóveis nas condições em que se constata o efeito da autocorrelação espacial tanto na variável dependente (defasagem espacial) quanto nos valores residuais (termo do erro). O efeito de defasagem espacial é ocasionado pela dependência espacial criada através de uma interação espacial entre os preços dos imóveis. Já a autocorrelação espacial residual está relacionada a erros de medida ocasionados pelas divisões artificiais das unidades territoriais, que não necessariamente coincidem com a verdadeira dimensão do fenômeno observado (DANTAS; MAGALHÃES; VERGOLINO, 2010).

Nesse estudo os testes de autocorrelação espacial indicaram uma maior predisposição para o efeito de interação espacial nos valores venais amostrais, de tal modo que as variáveis independentes não foram suficientes para proporcionar confiabilidade à predição do valor venal sem considerar os efeitos da autocorrelação espacial da variável dependente. Esse resultado é reforçado pelo fato de que a retirada das variáveis Utilização e Fachada, proporcionou um melhor alcance de qualidade do modelo da defasagem 
espacial, já que o critério de Akaike, recomendado pela Norma de Avaliação de Bens (NBR 14.653-2, p. 43) obteve o menor valor $(124,16)$ em detrimento do coeficiente de determinação $(0,89)$ que foi maior se comparado ao modelo com 9 variáveis. Somam-se a esse bom desempenho, a satisfação do critério de normalidade dos resíduos, o teste de homocedasticidade que indicou que os resíduos não foram enviesados, além de um ligeiro aumento na quantidade de valores preditos com erros inferiores a $20 \%$ e $50 \%$ em relação ao modelo clássico.

De acordo com a referida norma, a técnica de regressão espacial é recomendada quando for constatada a existência de autocorrelação espacial nos dados observados, de tal forma que esse procedimento tem se mostrado útil em avaliações em massa, PVG, estudos de velocidade de vendas e de demandas habitacionais (NBR 14.653-2, p. 42). Algumas experiências têm constatado que a modelagem dos efeitos espaciais e a sua incorporação em modelos clássicos de regressão têm melhorado as estimativas de variáveis relacionadas ao mercado imobiliário, proporcionando confidencialidade e a ausência de tendenciosidade. No município de São Gotardo (MG), a consideração dos efeitos espaciais melhorou a performance do modelo de regressão linear, evidenciando que a utilização indiscriminada do modelo clássico de regressão linear, sem considerar tais efeitos, pode levar a estimativas errôneas do valor venal dos imóveis (FILHO; BRITO; GONÇALVES, 2017). Na cidade do Recife, análises empíricas realizadas com o objetivo de estimar uma Função de Demanda por Habitação, indicaram fortes indícios de dependência espacial em todas as variáveis econômicas exploradas, comprovando-se a superioridade dos modelos espaciais em relação aos convencionais (DANTAS; MAGALHÃES; VERGOLINO, 2010).

Os modelos convencionais, econométricos ou hedônicos de preços procuram explicar o valor dos imóveis a partir da influência de variáveis explicativas, geralmente classificadas como variáveis construtivas e variáveis de localização. As variáveis ou fatores de localização que não são corretamente especificados e modelados podem gerar problemas nos modelos de regressão. Além da perda de poder de explicação do modelo, o tratamento incompleto ou inadequado de fatores de localização pode provocar a autocorrelação espacial nos resíduos do modelo que invalida uma das hipóteses básicas de aplicação do modelo de regressão e questiona a validade dos testes de hipótese da regressão tornando ineficientes as estimativas (TRIVELLONI, 2005). Existe grande probabilidade da presença de efeitos de dependência espacial em qualquer mercado habitacional, pelas características próprias do bem habitação, principalmente em relação à fixação espacial. No caso do efeito da defasagem espacial do valor venal, a formação dos preços de mercado da habitação não é explicada apenas pelas suas características estruturais, locacionais e temporais, tradicionalmente adotadas, mas também depende dos preços dos imóveis vizinhos (DANTAS; MAGALHÃES; VERGOLINO, 2010).

O modelo de RGP mostrou-se ser mais adequado para modelar os valores venais, isso pode indicar que além da presença de autocorrelação espacial dessa variável dependente, ela pode apresentar ausência de estacionariedade espacial, pois nessas condições, os coeficientes de regressão precisam refletir a heterogeneidade espacial. Os resultados desse estudo indicaram que o modelo mais adequado foi o de 7 variáveis, proporcionando um elevado poder de explicação $\left(R^{2}=0,97\right)$, além do valor mais inferior do critério de Akaike corrigido (-57,962). E apesar dos resultados dos testes de normalidade confirmarem a não aderência dos resíduos, a condição de homocedasticidade foi evidenciada, tal como os modelos com efeitos espaciais globais, além do fato de que a maioria dos valores preditos apresentaram erros de estimação inferiores a 20\%, faixa de erro considerada aceitável por Gazola (2002), e resultado semelhante ao obtido por Filho, Brito e Gonçalves (2017), através de um modelo de regressão com o efeito espacial global da componente erro. Esses autores obtiveram erros abaixo de $20 \%$ em $97,8 \%$ das amostras, embora valor de COD de $7,07 \%$, mais alto do que o obtido pelo modelo de RGP do atual estudo (3,89\%), que por si só está muito aquém do limite aceitável de $15 \%$ para imóveis residenciais unifamiliares, situados em áreas consolidadas ou heterogêneas, considerado pela $I A A O$ (2013).

Como o modelo de RGP reduzido proporcionou grande desempenho, o mesmo foi extrapolado para os imóveis não amostrados possibilitando o cálculo em massa dos valores venais. O critério de isenção do valor do IPTU foi baseado no código tributário de um município baiano, com características semelhantes a Itororó. Essa escolha se deve ao fato de que não foram encontrados documentos formais que estabelecesse esse tipo de critério para o município em questão. Sendo assim, considerando tal critério de isenção desse imposto, a arrecadação total de $\mathrm{R} \$ 96.859,94$ representaria 3,47\% da receita própria do município considerando o ano 
de 2018 que foi de $\mathrm{R} \$ 2.794 .044,64$ e 3,10\% no ano de 2019 (receita de $\mathrm{R} \$ 3.126 .819,63$ ) (TCMBA, 2019). No cenário hipotético de incremento da alíquota para $1 \%$ com o mesmo critério de isenção do IPTU, a arrecadação total aumentaria 567\% ( $\mathrm{R} \$ 645.732,95)$ o que proporcionaria uma maior representatividade da receita própria municipal: $23,11 \%$ no ano de 2018 e 20,65\% em 2019. Esses incrementos poderiam ter um impacto positivo para as contas municipais, uma vez que em 2019, apenas as despesas municipais com educação e saúde ultrapassaram muito a fonte de receita própria (R \$ 20.190.192.22), representando cerca de 43\% da receita total de $\mathrm{R} \$ 47.266 .833,64$ (própria + transferências) (TCMBA, 2019).

\section{CONCLUSÕES}

As transformações das variáveis proporcionaram ao MRLC qualidade satisfatória de modo a atender os requisitos básicos em conformidade com a Norma de Avaliação de Bens (NBR 14.653-2). Entretanto a constatação do efeito de interação espacial nos preços dos imóveis indicou que as variáveis independentes não são suficientes para proporcionar confiabilidade à predição do valor venal sem considerar os efeitos da autocorrelação espacial.

Assim, a incorporação desses efeitos através do modelo reduzido da defasagem espacial proporcionou um melhor poder de estimação e redução sutil no erro de predição em relação ao modelo clássico. No entanto a seleção de um terceiro modelo também reduzido, capaz de modelar a heterogeneidade espacial com coeficientes específicos para toda a área em estudo, mostrou-se mais adequado, capaz de propiciar a quase totalidade da explicação da variabilidade dos valores venais amostrais e redução brusca dos erros de predição e do COD quanto aos outros modelos.

O modelo de RGP desenvolvido nesse estudo proporcionou subsídios para a elaboração da PVG totais, mediante extrapolação do modelo e consequentemente simulação do impacto da arrecadação total do IPTU nas contas municipais. Desse modo o incremento na alíquota de $1 \%$ proporcionaria uma representatividade significativa, aumentando sua participação na receita própria municipal.

\section{Agradecimentos}

Os autores agradecem a contribuição de Felipe Costa, José Raimundo Soares e Mateus Soares pela elaboração do mapeamento geométrico básico e cadastro das informações dos imóveis.

\section{Contribuição dos Autores}

Este artigo foi resultado do trabalho de conclusão do curso de especialização em Geotecnologias: Soluções de Inteligência Geográfica do autor Felipe de Souza Pimenta, responsável pelo processamento e análise dos dados, inferência estatística, discussão dos resultados e elaboração do texto. O autor Frederico Vasconcelos Ribeiro contribuiu na disponibilização dos dados do cadastro imobiliário e mapeamento aerofotogramétrico e o autor Dionísio Costa Cruz Júnior contribuiu na revisão técnica do artigo.

\section{Conflitos de Interesse}

Os autores declaram que não há conflitos de interesse.

\section{Referências}

AFONSO, J. R. R.; ARAUJO, E. A.; NÓBREGA, M. A. R. O Imposto Predial e Territorial Urbano (IPTU) no Brasil. Um diagnóstico sobre o grau de aproveitamento do imposto como fonte de financiamento local. Cambridge: Lincoln Institute of Land Policy, n. 3, p. 1-48, 2010.

ANSELIN, L. Lagrange Multiplier Test Diagnostics for Spatial Dependence and Spatial Heterogeneity. Geographical Analysis, v. 20, n. 1, p. 1-17, January 1988. DOI.: 10.1111/j.1538-4632.1988.tb00159.x. 
ASSOCIAÇÃO BRASILEIRA DE NORMAS TÉCNICAS (ABNT). NBR 14.653-1: Avaliação de bens Parte 1: Procedimentos gerais, $1^{\mathrm{a}}$ ed, Rio de Janeiro, 2001.

ASSOCIAÇÃO BRASILEIRA DE NORMAS TÉCNICAS (ABNT). NBR 14.653-2: Avaliação de bens Parte 2: Imóveis urbanos, $2^{\mathrm{a}}$ ed, Rio de Janeiro, 2011.

BOHN, G. A.; BOHN, L. A. C. Modelo de regressão linear múltipla para avaliação de imóveis residenciais em Francisco Beltrão, Paraná. In: Congresso Técnico Científico da Engenharia e da Agronomia. Anais... Foz do Iguaçu, PR. 2016. p. 1-5.

BRASIL. Lei Complementar $n^{\circ}$. 101, de 4 de maio de 2000. Estabelece normas de finanças públicas voltadas para a responsabilidade na gestão fiscal e dá outras providências. Diário Oficial da República Federativa do Brasil, Brasília, DF. 4 de maio de 2000.

CARVAlHO, L. E. X.; SILVA, H. N.; LOUREIRO, C. F. G.; MENESES, H. B. Regressão linear geograficamente ponderada em ambiente SIG. Transportes, v. 14, n. 2, p. 18-26, 2006. DOI.: 10.14295/transportes.v14i2.65.

CONFEDERAÇÃO NACIONAL DOS MUNICÍPIOS (CNM). Estimativa Populacional 2018. Estudos Técnicos, Brasília, Agosto de 2017. Disponível em: <https://www.cnm.org.br/cms/biblioteca/Estimativa\%20Populacional\%202018.pdf>, Acesso em fevereiro de 2019.

CONFEDERAÇÃO NACIONAL DOS MUNICÍPIOS (CNM). O Comportamento das Finanças Municipais2017. Estudos Técnicos, Brasília, Maio de 2018. Disponível em: <https://www.cnm.org.br/cms/biblioteca/Comportamento\%20das\%20Finan\%C3\%A7as\%20Municipais \%20-\%202017.pdf>, Acesso em fevereiro de 2019.

CONFEDERAÇÃO NACIONAL DOS MUNICÍPIOS (CNM). Monitor: O Boletim das Finanças Municipais. Boletim, Brasília, Dezembro de 2019. Disponível em: < https://www.cnm.org.br/cms/biblioteca/Monitor\%20-

$\% 20$ Por\%20dentro\%20de\%203\%20fontes\%20de\%20receita\%20(ed.\%2007)\%20(2019).pdf>, Acesso em setembro de 2020.

DANTAS, R. A.; MAGAlhãeS, A. M.; VERGOlinO, J. R. O. Um modelo espacial de demanda habitacional para a cidade do Recife. Estudos Econômicos, v. 40, n. 4, p. 891-916, Oct./Dec. 2010. DOI.: 10.1590/S0101-41612010000400006.

DUARTE, D. C. O. Cadastro técnico multifinalitário com uso de sistema de informação geográfica aplicado à gestão pública de municípios de pequeno porte. 2014. 92 f. Dissertação (Mestrado) Programa de Pós-Graduação em Engenharia Civil, Universidade Federal de Viçosa, Viçosa, MG, 2014.

FILHO, R. F. F.; BRITO, J. L. S.; GONÇALVES, R. M. L. Modelos estatísticos para geração de plantas de valores genéricos em áreas urbanas. Gestão \& Produção, v. 24, n. 2, p. 279-294, 2017. DOI.: 10.1590/0104-530x2482-15.

GALVÃO, G. M.; ROSALEN, D. L. Acurácia da mosaicagem gerada por veículo aéreo não tripulado utilizado na agricultura de precisão. In: FURLANI, C. E. A.; SILVA, R. P.; ROSALEN, D. L. (Orgs.). $42^{\circ}$ CONGRESSO BRASILEIRO DE ENGENHARIA AGRÍCOLA: OS DESAFIOS PARA O DESENVOLVIMENTO SUSTENTÁVEL. 1ed. SBEA, Jaboticabal, SP, 2013.

GAZOLA, S. Construção de um modelo de regressão para avaliação de imóveis. 2002. 140 f. Dissertação (Mestrado) - Programa Pós-Graduação em Engenharia de Produção, Universidade Federal de Santa Catarina, Florianópolis, 2002.

INTERNATIONAL ASSOCIATION OF ASSESSING OFFICERS (IAAO). Standard on ratio studies, 2013. Disponível em: <https://www.iaao.org/media/standards/Standard_on_Ratio_Studies.pdf/_, Acesso em outubro de 2019.

JOHNSON, N. L. Systems of Frequency Curves Generated by Methods of Translation. Biometrika, v. 36, n. 1/2, p. 149-176, June 1949. DOI.: 10.2307/2332539.

OLIVEIRA, R. F.; RAMOS, A. P. M.; MALAMAN, C. S.; AMORIM, A. Análise de modelos de regressão 
linear múltipla para elaboração de planta de valores genéricos. In: COBRAC, 2016, Florianópolis. Anais... Florianópolis, 2016, p. 1-14.

PAIVA, C. A.; ANTUNES, A. F. B. A. Geração de planta de valores genéricos a partir do cadastro territorial urbano. Revista Brasileira de Cartografia, v. 3, n. 69, p. 505-518, Março, 2017.

PERFIL FINANCEIRO DOS MUNICÍPIOS BAIANOS 2010-2013 (PFMB). Superintendência de Estudos Econômicos e Sociais da Bahia e Tribunal de Contas dos Municípios do estado da Bahia. v. 8, p. 1196, Salvador, 2015.

TRIBUNAL DE CONTAS DOS MUNICÍPIOS DO ESTADO DA BAHIA (TCMBA). Município de Itororó, 2019. Disponível em: <http://www.tcm.ba.gov.br/municipio-post/itororo/>, Acesso em setembro de 2020.

TRIVELLONI, C. A. P. Método para determinação do valor da localização com uso de técnicas inferenciais e geoestatísticas na avaliação em massa de imóveis. 2005. 172 f. Tese (Doutorado) Programa Pós-Graduação em Engenharia Civil, Universidade Federal de Santa Catarina, Florianópolis, 2005.

YEO, I. K.; JOHNSON, R. A. A New Family of Power Transformation to Improve Normality or Symmetry. Biometrika, v. 87 , n. 4, p. 954-959, December 2000. Disponível em: <https://www.jstor.org/stable/2673623>. Acesso em: 02 fev. 2021.

\section{Biografia do autor principal}

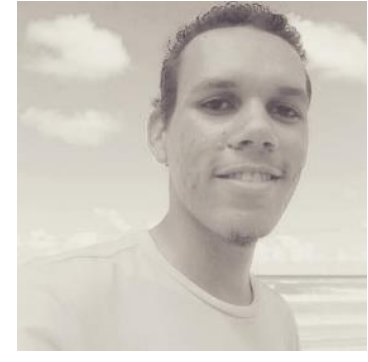

Felipe de Souza Pimenta, Itabuna (BA), 1993. Geógrafo pela Universidade Estadual de Santa Cruz (UESC), Especialista em Geotecnologias: Soluções de Inteligência Geográfica pela Escola de Engenharia de Agrimensura (EEA) e Mestre em Desenvolvimento Regional e Meio Ambiente (UESC). Atuou em projetos de consultoria na área ambiental e de agrimensura e atualmente desempenha funções de analista de geoprocessamento pelo grupo Zago, prestando serviços à Secretaria do Patrimônio da União do Espírito Santo em atividades de produção e padronização cartográfica sob a luz da Infraestrutura Nacional de Dados Espaciais. 